\title{
Periostite reativa florida da falange proximal - relato de caso e revisão de literatura*
}

\section{Florid Reactive Periostitis of the Proximal Phalanx - Case Report and Literature Review}

\author{
José Neias Araujo Ribeiro ${ }^{1}$ Maria Luzete Costa Cavalcante ${ }^{10}$ Diogo Araujo Farias Junior ${ }^{1}$ \\ Rudy Diavila Bingana² \\ ${ }^{1}$ Departamento de Ortopedia, Universidade Federal do Ceará, \\ Hospital Walter Cantídio, Fortaleza, CE, Brasil \\ 2 Faculdade de Medicina, Universidade Federal do Ceará, Fortaleza, \\ CE, Brasil \\ Address for correspondence Maria Luzete Costa Cavalcante, Rua
Professor Costa Mendes, 1608, Rodolfo Teófilo, Fortaleza, CE, Brasil.
CEP: $60430-140$. \\ (e-mail: marialuzetecosta@gmail.com; joseneias2@yahoo.com.br).
}

Rev Bras Ortop 2019;54:335-338.

\section{Resumo \\ Palavras-chave \\ - falanges dos dedos da mão \\ - periostite \\ - neoplasias ósseas}

A periostite reativa florida é uma lesão benigna e rara que constitui um problema recorrente de diagnóstico. Sua etiopatogênese permanece desconhecida. A periostite reativa florida caracteriza-se por ser uma reação periosteal agressiva e inflamatória de tecido mole e por ser um tumor portador de fibrose e produtor de cartilagem. Ocorre em adolescentes e adultos jovens, com predomínio no sexo feminino, e acomete com frequência os ossos das mãos e pés, podendo acometer também ossos longos. O diagnóstico permanece um grande desafio devido à enorme possibilidade de diagnósticos diferenciais. Por isso, uma cuidadosa avaliação clínica, radiológica e patológica é necessária para fechar o diagnóstico. Relata-se o caso de um paciente com periostite reativa florida na falange proximal do segundo dedo da mão direita, que foi submetida à excisão cirúrgica com margem ampla do segundo raio até o terço proximal do segundo metacarpo, e evoluiu sem queixas, com amplitude de movimento e força satisfatória.

Florid reactive periostitis is a benign and rare lesion that is a recurrent diagnostic problem. Its etiopathogenesis remains unknown. Florid reactive periostitis consists of an aggressive periosteal reaction and inflammatory soft tissue, and a fibrosis tumor, which produces cartilage. It typically occurs in adolescents and young adults, predominantly female, often affects the bones of the hands and feet, and may affect long bones. Its diagnosis remains a major challenge due to the vast possibility of differential diagnoses. Therefore, careful clinical, radiological and pathological evaluation is required to make the diagnosis. We report the case of a patient with florid reactive periostitis in the proximal phalanx of the second finger of the right hand, who underwent surgical excision with a wide margin from the second ray to the third proximal of the second metacarpal, and evolved without complications, with range of motion and satisfactory strength.

* Trabalho feito na Universidade Federal do Ceará, Hospital Walter Cantídio, Fortaleza, CE, Brasil.

(1) Maria Luzete Costa Cavalcante's ORCID is https://orcid.org/00000002-3363-6916.

received

July 28, 2017

accepted

July 2, 2018
DOI https://doi.org/

10.1055/s-0039-1692430. ISSN 0102-3616.
Copyright $\odot 2019$ by Sociedade Brasileira License terms de Ortopedia e Traumatologia. Published by Thieme Revnter Publicações Ltda, Rio de Janeiro, Brazil 


\section{Introdução}

A periostite reativa florida é uma lesão benigna e rara, fazendo parte de uma família de lesões reativas do osso e dos tecidos moles que constituem um problema recorrente de diagnóstico. Uma das primeiras descrições da lesão remonta da década de 1930, quando Mallory ${ }^{1}$ relatou 6 casos, sendo que 4 apresentavam lesões tumorais semelhantes, senão idênticas à periostite reativa. Cerca de 30 anos depois, Hutter et $\mathrm{al}^{2}$ propuseram a denominação "fasciíte parosteal" porque histologicamente se assemelhava à fasciíte nodular de partes moles, e o termo "paraosteal" localizava anatomicamente a lesão.

A periostite reativa florida é mais frequente na $2^{\mathfrak{a}}$ e $3^{\text {a }}$ décadas de vida, apesar de que a faixa etária relatada na literatura é de 5 a 70 anos. $^{3-5}$ De acordo com Fechner et al, ${ }^{6}$ a proporção da incidência entre homens e mulheres é de 1 para 1,5. A lesão é comumente encontrada em falanges das mãos, sendo a falange proximal a mais acometida.

Esta patologia é uma entidade caracterizada por uma exuberante produção de osteoblastos em um fibroso estroma proliferativo originada em nível do periósteo dos dedos. O estudo radiográfico apresenta-se com aumento de partes moles e neoformação óssea periosteal, que pode ter um aspecto lamelar ou de osso maduro. A cortical geralmente está intacta.

No diagnóstico diferencial, devemos incluir tenossinovite séptica, abscesso de partes moles, tumores ósseos, osteomielite cortical, miosite ossificante, tumores benignos de célula gigante, osteossarcoma e outros.

No presente estudo de caso, discutimos a história clínica, a radiologia, a histologia e o tratamento de uma paciente com periostite reativa florida em falange proximal do segundo dedo da mão direita.

\section{Relato de Caso}

Paciente, 17 anos, sexo feminino, com história de lesão tumoral no segundo quirodáctilo da mão direita com evolução nos últimos 4 anos. Há 3 anos, ela procurou atendimento médico devido ao crescimento da lesão. Em maio de 2014, foi realizada uma biópsia. Os cortes histológicos mostraram traves ósseas maduras, envolvendo células adiposas típicas dispostas em lençóis, além de leve infiltrado inflamatório linfonodular. Em setembro de 2014, a paciente foi submetida a uma tomografia que evidenciou uma volumosa exostose óssea na falange proximal do segundo raio medindo $4,2 \times 3,3 \times 2,2 \mathrm{~cm}$, com contornos lobulados $\mathrm{e}$ bem definidos, com área de afilamento cortical, porém sem ruptura desta ou extensão para partes moles adjacentes (-Fig. 1).

Em janeiro de 2015, foi realizado novo estudo histopatológico que evidenciou tecido cartilaginoso, contendo condrócitos de núcleos amplos e matriz calcificada, associado a trabéculas ósseas permeadas por tecido adiposo sem atipias, sugestivo de periostite florida de Nora.

A paciente compareceu ao ambulatório em abril de 2015, relatando déficit de flexão do dedo afetado. No exame físico, apresentava crescimento tumoral sólido localizado na falange proximal do segundo dedo, medindo $3,0 \times 2,5 \mathrm{~cm}$. Na ocasião, foi solicitado estudo radiográfico da mão direita, o qual evidenciou ampla massa tumoral em toda falange proximal do segundo quirodáctilo (-Fig. 2).

A terceira biópsia incisional demonstrou trabéculas ósseas permeadas por tecido adiposo, associado à área de proliferação fusocelular de aspecto ativado em meio à deposição de matriz colágeno, com baixa atividade mitótica e ausência de necrose, quadro compatível com periostite florida. Foi programado procedimento cirúrgico, porém, este não foi realizado devido à gravidez da paciente, tendo esta retornado após 11 meses.

No retorno, ao exame físico, observou-se um aumento da lesão com as seguintes características macroscópicas: bordas irregulares, circunferenciais e medindo $6,0 \times 4,5 \mathrm{~cm}$. Foi então solicitada uma ressonância magnética (RM) da mão direita, a qual evidenciou uma lesão óssea expansiva, vegetante, medindo $4,1 \times 1,9 \times 3,2 \mathrm{~cm}$, encoberta por fina

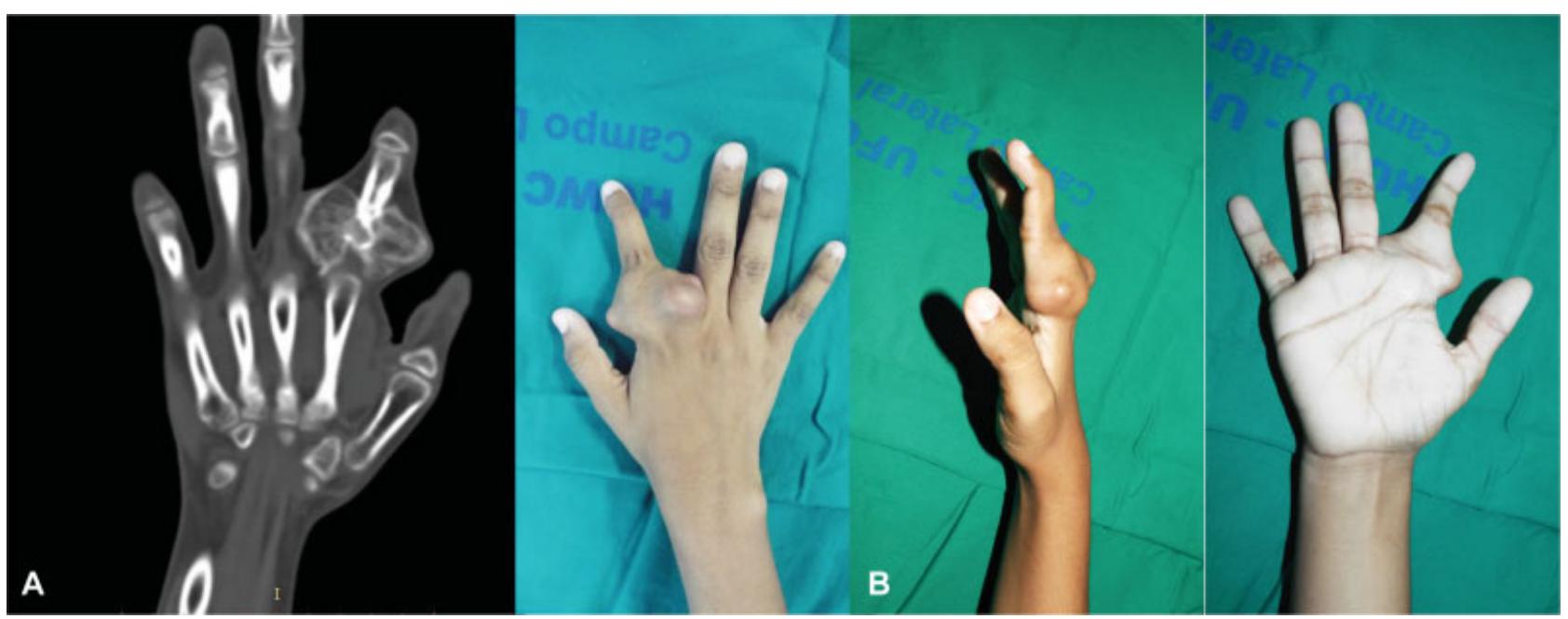

Fig. 1 Tomografia computadorizada em corte coronal da mão direita evidenciando uma lesão insuflativa com afilamento, esclerose da cortical e reação periostial em falange proximal do segundo dedo (A); Aspecto clínico da mão no pré-operatório, com limitação funcional do segundo dedo $(B)$. 


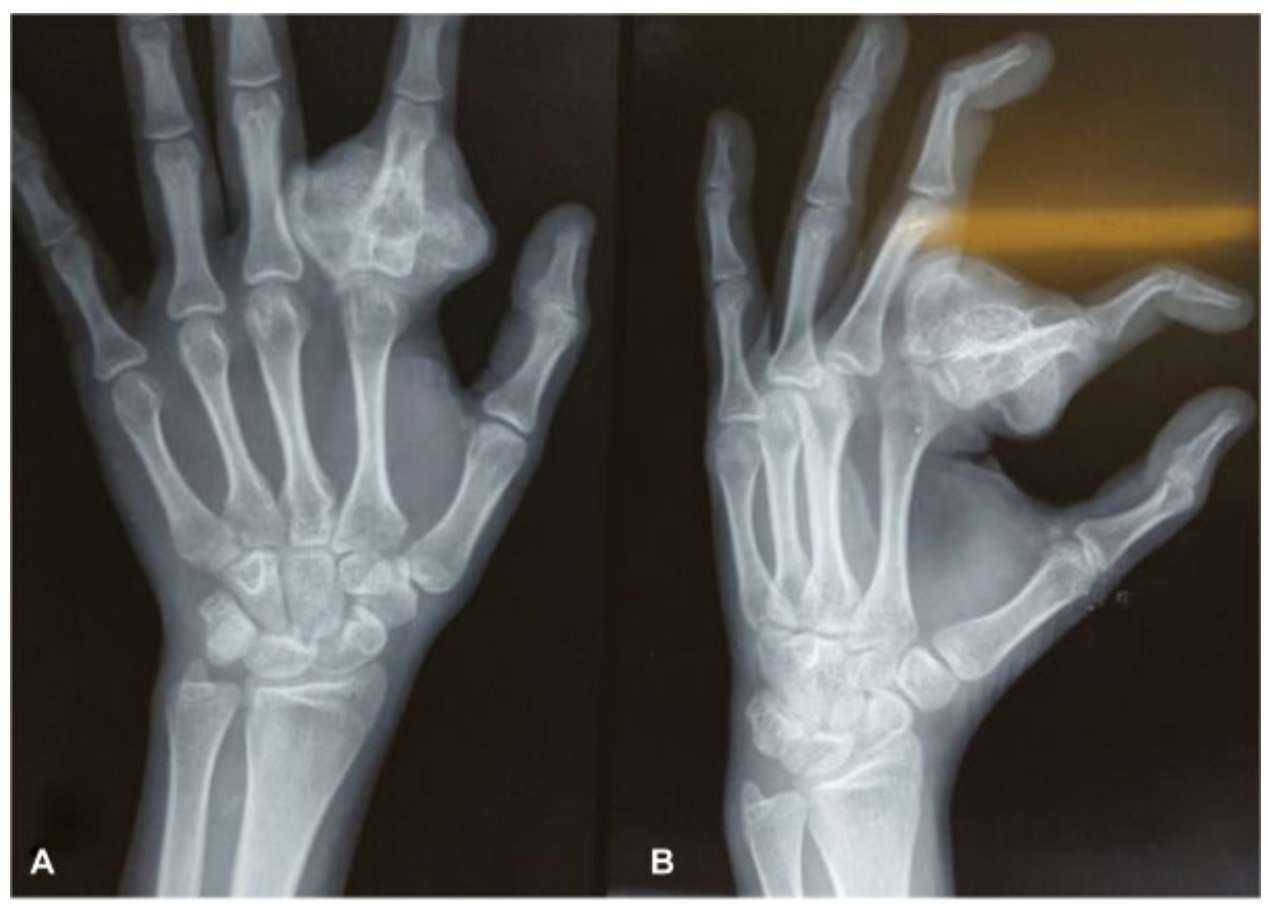

Fig. 2 Radiografia em anteroposterior: observe edema e massa ossificada de partes moles em toda falange proximal do segundo quirodáctilo (A) e radiografia em obliqua: evidência de extensão tumoral intra-articular (B).

lâmina de cartilagem, pedunculada à metáfise do metacarpo do segundo quirodáctilo ( - Fig. 3 ).

Com os resultados da biópsia e exames de imagem, foi realizada excisão cirúrgica com margem ampla do segundo raio até o terço proximal do segundo metacarpo (-Fig. 4).

A paciente evoluiu sem queixas do aspecto estético, sem dor, com amplitude de movimento e força satisfatória.

\section{Discussão}

A periostite reativa florida é uma condição benigna que pode mimetizar uma osteomielite ou uma neoplasia maligna óssea pelas suas características clínicas e radiológicas. Apesar de ser uma condição benigna, a apresentação clínica geralmente é alarmante e requer exclusão de outras condições patológicas, tais como as osteomielites, o osteocondroma, os tumores de células gigantes da bainha do tendão, o condrossarcoma e o osteossarcoma paraosteal.

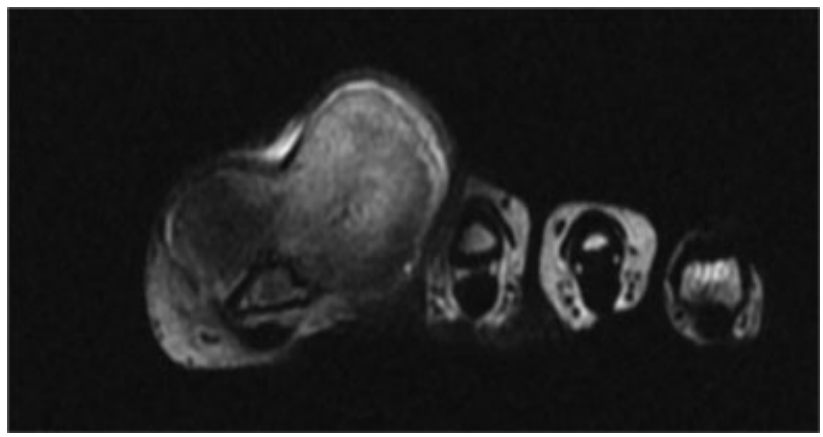

Fig. 3 Ressonância magnética em corte axial da mão direta mostrando uma lesão óssea expansiva, com delgada lâmina de cartilagem e acometimento de partes moles.
A avaliação radiológica revela edema ou massa ossificada de partes moles, às vezes acompanhada de neoformação do osso periosteal. ${ }^{4,7,8}$ A RM revela de forma clara a massa de tecidos moles, o que é dificilmente evidenciado pela radiografia. A tomografia computadorizada (TC) pode evidenciar melhor a erosão ou a destruição óssea. ${ }^{8}$

O diagnóstico final é histológico, com evidência de formação osteoide, massa óssea e cartilaginosa no meio de um fundo de estroma fibroproliferativo. O componente fibroso é constituído por grande eixo de núcleos, mas não de mitoses

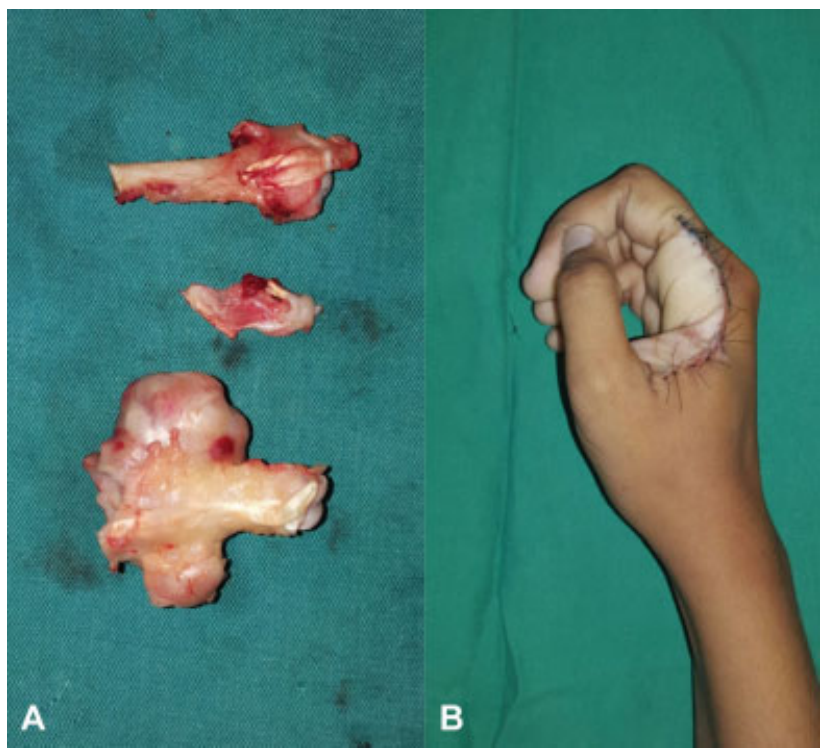

Fig. 4 Fotografia das peças cirúrgicas após a exérese da lesão (A) e observe o aspecto pós-cirúrgico imediato (B). 
atípicas. Células gigantes e células inflamatórias em quantidade variável podem ser notadas. ${ }^{3-5}$

A periostite reativa florida pode ser facilmente confundida com outras patologias sérias. É difícil diferenciar a periostite florida da proliferação osteocondromatosa paraosteal bizarra (do inglês "Bizarre parosteal osteochondromatous proliferation" [BPOP, na sigla em inglês]). A BPOP, também conhecida como lesão de Nora, é rara, porém de comportamento agressivo.

A exostose de Turret ou osteocondroma adquirido é uma doença óssea rara em forma de cúpula, que nasce no dorso da falange proximal e média dos dedos. ${ }^{2}$

A miosite ossificante, a exostose subungueal, o osteossarcoma, o osteossarcoma periosteal, o condroma periosteal e o condrossarcoma periosteal também fazem parte do diagnóstico diferencial. A falta de pleomorfismo celular e de figuras mitóticas atípicas na avaliação histológica permite diferenciar a periostite reativa florida das lesões malignas. ${ }^{4}$

Alguns autores concordam que a ressecção local e completa do tumor é suficiente para o tratamento completo. ${ }^{9}$ Entretanto, outros autores referem presença de recidivas, 3,4 o que pode levar a uma ressecção adicional. ${ }^{9}$ Patel et al, ${ }^{10}$ após revisão de literatura, recomendaram aplicar o sistema de estadiamento cirúrgico de Enneking ${ }^{11}$ para tumores benignos nos casos de periostite reativa florida, a fim de considerar as diferenças de recorrência do tumor. Eles concluíram que a ressecção local seria apropriada para tumores menos agressivos grau I, porém não suficiente para tumores grau II e III, sendo necessária a amputação do raio para prevenir recidiva. ${ }^{10}$ Neste caso, a paciente se enquadrava no estagio III de Enneking, ${ }^{11}$ por isso foi feita a opção pela excisão cirúrgica com margem ampla.

O diagnóstico de periostite reativa florida permanece um desafio devido ao grande leque de diagnósticos diferenciais, principalmente com entidades malignas. Por isso, uma cuidadosa avaliação clínica, radiológica e patológica é necessária para estabelecer o diagnóstico adequado.

Conflitos de Interesses

Os autores declaram não haver conflitos de interesses.

\section{Referências}

1 Mallory TB. A Group of Metaplastic and Neoplastic Bone- and Cartilage-Containing Tumors of Soft Parts. Am J Pathol 1933;9 (Suppl):765-776, 3

2 Hutter RV, Foote FW, Francis KC, Higinbotham NL. Parosteal fascitis. A self-limited benign process that simulates a malignant neoplasm. Am J Surg 1962;104:800-807

3 Spjut HJ, Dorfman HD. Florid reactive periostitis of the tubular bones of the hands and feet. A benign lesion which may simulate osteosarcoma. Am J Surg Pathol 1981;5(05):423-433

4 Rogers GF, Brzezienski MA. Florid reactive periostitis of the middle phalanx: a case report and review of the literature. J Hand Surg Am 1999;24(05):1014-1018

5 Dupree WB, Enzinger FM. Fibro-osseous pseudotumor of the digits. Cancer 1986;58(09):2103-2109

6 Fechner RE, Mills SE. Tumors of the Bones and Joints (Atlas of Tumor Pathology Series IV). Washington DC: Armed Forced Institute Pathology; 1993:268-269

7 Solana J, Bosch M, Español I. Florid reactive periostitis of the thumb: a case report and review of the literature. Chir Main 2003; 22(02):99-103

8 Gao Z, Wang J, Wang Z, Meng Q. Florid reactive periostitis of the metacarpal and phalanx: 2 case reports. J Hand Surg Am 2013;38 (11):2134-2137

9 Howard RF, Slawski DP, Gilula LA. Florid reactive periostitis of the digit with cortical erosion: a case report and review of the literature. J Hand Surg Am 1996;21(03):501-505

10 Patel MR, Desai SS. Pseudomalignant osseous tumor of soft tissue: a case report and review of the literature. J Hand Surg Am 1986;11 (01):66-70

11 Enneking WF. Staging of musculoskeletal neoplasms. In: Uhthoff HK, Stahl E, eds. Current concepts of diagnosis and treatment of bone and soft tissue tumors. Berlin: Springer-Verlag; 1984:1-21 